\title{
Interfaces and ventilator settings for long-term noninvasive ventilation in COPD patients
}

\author{
This article was published in the following Dove Press journal: \\ International Journal of COPD \\ 28 June 2017 \\ Number of times this article has been viewed
}

Jens Callegari'

Friederike Sophie Magnet'

Steven Taubner'

Melanie Berger ${ }^{2}$

Sarah Bettina Schwarz'

Wolfram Windisch'

Jan Hendrik Storre ${ }^{3,4}$

'Department of Pneumology, Cologne-Merheim Hospital, Kliniken der Stadt Koeln, Witten/Herdecke University Hospital, ${ }^{2}$ Department of Pneumology, Malteser Hospital St Hildegardis, Cologne, ${ }^{3}$ Department of Pneumology, University Medical Hospital, Freiburg, ${ }^{4}$ Department of Intensive Care, Sleep Medicine and Mechanical Ventilation, Asklepios Fachkliniken Munich-Gauting, Gauting, Germany
Correspondence: Jan Hendrik Storre Department of Intensive Care, Sleep Medicine and Mechanical Ventilation, Asklepios Fachkliniken Munich-Gauting, Robert-Koch-Allee 2, D-82।3 |

Gauting, Germany

Tel +4989857910

Fax +4989857914306

Email j.storre@asklepios.com
Introduction: The establishment of high-intensity (HI) noninvasive ventilation (NIV) that targets elevated $\mathrm{PaCO}_{2}$ has led to an increase in the use of long-term NIV to treat patients with chronic hypercapnic COPD. However, the role of the ventilation interface, especially in more aggressive ventilation strategies, has not been systematically assessed.

Methods: Ventilator settings and NIV compliance were assessed in this prospective crosssectional monocentric cohort study of COPD patients with pre-existing NIV. Daytime arterialized blood gas analyses and lung function testing were also performed. The primary end point was the distribution among study patients of interfaces (full-face masks [FFMs] vs nasal masks [NMs]) in a real-life setting.

Results: The majority of the 123 patients studied used an FFM (77\%), while 23\% used an NM. Ventilation settings were as follows: mean \pm standard deviation (SD) inspiratory positive airway pressure (IPAP) was $23.2 \pm 4.6$ mbar and mean \pm SD breathing rate was $16.7 \pm 2.4$ /minute. Pressure support ventilation (PSV) mode was used in $52.8 \%$ of patients, while assisted pressure-controlled ventilation (aPCV) was used in $47.2 \%$ of patients. Higher IPAP levels were associated with an increased use of FFMs (IPAP $<21$ mbar: $73 \%$ vs IPAP $>25$ mbar: 84\%). Mean compliance was 6.5 hours/day, with no differences between FFM (6.4 hours/day) and $\mathrm{NM}$ (6.7 hours/day) users. $\mathrm{PaCO}_{2}$ assessment of ventilation quality revealed comparable results among patients with FFMs or NMs.

Conclusion: This real-life trial identified the FFM as the predominantly used interface in COPD patients undergoing long-term NIV. The increased application of FFMs is, therefore, likely to be influenced by higher IPAP levels, which form part of the basis for successful application of HI-NIV in clinical practice.

Keywords: compliance, home mechanical ventilation, interfaces, masks, pressure support, ventilation modes

\section{Introduction}

COPD patients with chronic hypercapnic respiratory failure are increasingly treated with long-term noninvasive ventilation (NIV) due to its association with improved survival rates, better health-related quality of life (HRQL) and increased exercise capacity after treatment commencement. ${ }^{1-3}$ Despite this, some studies have reported negative effects of long-term NIV, raising the need for both the establishment of ideal ventilation settings and the optimal time point for NIV initiation. ${ }^{4-7}$

In recent positive trials, high-intensity (HI)-NIV was applied with the aim of maximally reducing $\mathrm{PaCO}_{2}$ via high inspiratory positive airway pressures (IPAPs) and backup breathing rates, thus favoring an assisted pressure-controlled ventilation (aPCV) mode. ${ }^{1,2}$ While the benefits of more aggressive forms of NIV targeting elevated $\mathrm{PaCO}_{2}$ values are undisputed, ${ }^{2}$ the precise role of the ventilation interface 
in this setting remains unknown, even though it has been highlighted as a key factor for successful NIV. ${ }^{8}$ Data from the Eurovent trial revealed that $80 \%$ of patients with lung disease undergoing long-term NIV used nasal masks (NMs). ${ }^{9}$ Of note, HI-NIV was not frequently used around the time these data were collected. While recent expert surveys suggested a switch from NMs to oro-nasal masks or full-face masks (FFMs) in $>50 \%$ of COPD patients using interfaces, this was attributed to expert opinions rather than real clinical data. ${ }^{10}$ Of note, physiological studies revealed better patient compliance with NMs, ${ }^{11,12}$ whereas alveolar ventilation was improved with FFMs. ${ }^{12}$ Nevertheless, these findings have little relevance to the HI-NIV conditions used in COPD patients, since low IPAP levels were used and the number of COPD patients included was also low. ${ }^{11,12}$

Since a systematic investigation of interface use in longterm HI-NIV in COPD is still lacking, this real-life study was designed to evaluate the interface distribution among COPD patients undergoing long-term NIV. Randomized controlled trials (RCTs) with predefined inclusion and exclusion criteria were omitted to create a real-life NIV setting in which ventilator settings, patient compliance relative to different inspiratory pressure ranges and mask selection were each assessed.

\section{Methods}

This prospective, cross-sectional, single-center, observational cohort study was carried out in the respiratory care unit at the Department of Pneumology, Cologne-Merheim Hospital, University of Witten/Herdecke, Germany. The study was approved by the ethics committee of the University of Witten/ Herdecke and performed in accordance with the Declaration of Helsinki. The study was registered at the German Clinical Trials Register (DRKS00008759). Written informed consent was obtained from all subjects.

\section{Subjects}

Between June 2015 and April 2016, all patients already undergoing noninvasive home mechanical ventilation (HMV) were screened for eligibility both during follow-up care visits (inpatient and outpatient service) and upon admission to the hospital due to acute exacerbation. Patients who had only used long-term NIV for $<4$ weeks and did not have underlying COPD were excluded from the study. The initiation of NIV therapy for COPD patients was performed according to national guidelines ${ }^{13}$ and previous studies, ${ }^{1-3}$ with the aim of maximally reducing arterial $\mathrm{CO}_{2}$ according to the patients' level of tolerance.
Patients defined as "NIV initiation after acute exacerbation" received HMV for hypercapnia that persisted following an acute exacerbation and were enrolled during subsequent follow-up visits or readmissions.

\section{Data collection}

The following data were collected: demographics, including age, sex and body mass index (BMI); smoking status and pack-years; date of and reason for NIV initiation and comorbidities.

NIV settings were adopted directly from the ventilator prior to any changes. Patient compliance (NIV usage in hours/24 hours) was determined by a readout of the ventilator's built-in software. Data were collected on the following: ventilator type, mask type, exhalation valve and tubing system, ventilation modes, IPAPs and expiratory positive airway pressures (EPAPs), backup breathing rates, inspiratory time and use of an additional active humidification system.

Diurnal arterial blood gas (ABG) samples were taken from the arterialized earlobe, while oxygen was supplied according to the patient's individual needs (ALB800 Flex Radiometer). Only patients recruited during routine follow-up care were enrolled for ABG analysis. ABG samples from unstable patients requiring hospitalization were not analyzed. Body plethysmography was performed in stable patients when possible.

\section{Statistics}

Demographic data, lung function parameters and diurnal ABGs were analyzed in all patients. Different patient groups were classified according to pressure levels: IPAP $<21 \mathrm{mbar}$, IPAP range 21-25 mbar and IPAP $>25$ mbar. This selection was based on previous studies. ${ }^{1-7}$

Sample-size planning was based on the primary end point "extent of FFM use" using exact binomial distribution. The study showed with a one-sided significance level of $2.5 \%$ that FFMs were used in $>30 \%$ of the patients. To achieve this with $90 \%$ power under an assumption rate of $50 \%$, the study needed to enroll 66 patients. The rate of FFM compared to NM use was estimated with a $95 \%$ confidence interval (CI). Further subgroup analyses of mask distribution among patients and in relation to ventilation characteristics were performed descriptively.

\section{Results}

A total of 172 patients were screened for eligibility, and 49 of them were excluded ( 5 patients refused to participate and 44 patients were non-COPD). A total of 123 patients with 
COPD and pre-existing NIV were, therefore, enrolled and analyzed (Figure 1). During the course of the study, the sample size became larger due to an unexpected increase in patient recruitment, thus improving the power of findings.

The percentage of patients with FFMs vs NMs was $77.2 \%$ vs $22.8 \%$, respectively ( $95 \%$ CI $68.8 \%-84.3 \%$ ). Therefore, the study achieved its aim of showing that FFMs are the predominant interfaces for long-term NIV in COPD patients.

Patient characteristics are summarized in Table 1. Here, $74.8 \%(n=92)$ of patients were recruited during routine follow-up appointments, whereas $25.2 \%(n=31)$ were enrolled during the course of an acute exacerbation.

Ventilation settings and interfaces are summarized in Table 2. A total of 30 different masks were used among patients: six patients had individually fitted masks, one used a nasal pillow mask and two had total-face masks. For further analysis, nasal pillow masks and total-face masks were classified as NMs and oro-nasal masks, respectively. Five patients used two different types of masks on a rotational basis. Figure 2 highlights the variation in mask distribution among patient subgroups.

Data on the daily usage of NIV were not available in two patients due to software problems. The mean overall compliance was 6.5 hours/day. In all, $70 \%$ of patients $(n=85)$ had an NIV adherence of $\geq 5$ hours, while $6 \%$ of patients ( $n=7$ ) had a daily adherence of $<1$ hour. Subgroup (FFMs vs NMs) analyses of compliance (Figure 3) and daytime $\mathrm{PaCO}_{2}$ (Figure 4) were given according to IPAP ranges. Figure 5 shows the patient distribution of interfaces, ventilation modes and equipment relative to the pre-set IPAP ranges.

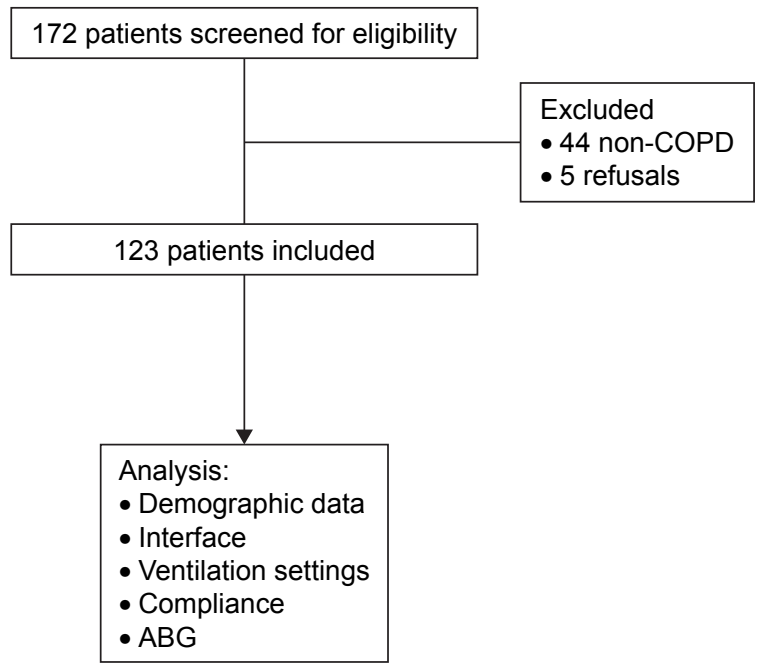

Figure I Flow chart of study design and patient recruitment. Abbreviation: ABG, arterial blood gas.
Table I Demographic data and lung function parameters

\begin{tabular}{|c|c|c|c|}
\hline Variable & $N=123$ & Min & Max \\
\hline Female (\%) & $44.7(55)$ & - & - \\
\hline Age (years) & $66.4 \pm 7.9$ & 48.7 & 85.1 \\
\hline BMI $\left(\mathrm{kg} / \mathrm{m}^{2}\right)$ & $27.6 \pm 7.8$ & 14.4 & 54.7 \\
\hline Pack-years & $55.4 \pm 25.4$ & 12 & 150 \\
\hline NIV use (years) & $2.3 \pm 2.8$ & 0.1 & 15.1 \\
\hline Use of LTOT (\%) & $80.5(99)$ & - & - \\
\hline History of IMV due to ARF (\%) & $26.8(33)$ & - & - \\
\hline \multicolumn{4}{|l|}{ NIV initiation after } \\
\hline Acute exacerbation & $60.2(74)$ & - & - \\
\hline Weaning from IMV & $4.1(5)$ & - & - \\
\hline Chronic hypercapnia & $35.7(44)$ & - & - \\
\hline $\mathrm{FEV}_{1}(\%$ predicted $)$ & $34.1 \pm 13.1 *$ & - & - \\
\hline FVC (\% predicted) & $56.2 \pm 15.4^{*}$ & - & - \\
\hline $\mathrm{FEV}_{\mathrm{l}} / \mathrm{FVC}(\%)$ & $50.1 \pm 16.5^{*}$ & - & - \\
\hline RV (\% predicted) & $213 \pm 77.1 *$ & - & - \\
\hline TLC (\% predicted) & $110 \pm 29.9 *$ & - & - \\
\hline DLCO (\% predicted) & $59.6 \pm 16.1 * *$ & - & - \\
\hline $\mathrm{PCO}_{2}(\mathrm{mmHg})$ & $47.2 \pm 7.7 * * *$ & - & - \\
\hline $\mathrm{PO}_{2}(\mathrm{mmHg})$ & $64.5 \pm 12.4^{* * *}$ & - & - \\
\hline $\mathrm{pH}$ value & $7.4 \pm 0.03 * * *$ & - & - \\
\hline $\mathrm{HCO}_{3}^{-}(\mathrm{mmol} / \mathrm{L})$ & $27.7 \pm 3.3 * * *$ & - & - \\
\hline
\end{tabular}

Notes: Data presented as mean \pm standard deviation or $\%$ of patients $(n=)$; data in brackets represent $n=x$. ${ }^{*} n=51 . *^{*} n=42$. ${ }^{* * *} n=92$. The "-" symbols indicate not applicable.

Abbreviations: Min, minimum; Max, maximum; BMI, body mass index; NIV, noninvasive ventilation; LTOT, long-term oxygen therapy; IMV, invasive mechanical ventilation; ARF, acute respiratory failure; $\mathrm{FEV}_{1}$, forced expiratory volume in I second; FVC, forced vital capacity; RV, residual volume; TLC, total lung capacity; $\mathrm{DLCO}$, diffusing capacity for carbon monoxide; $\mathrm{PCO}_{2}$, partial pressure of carbon dioxide; $\mathrm{PO}_{2}$, partial pressure of oxygen; $\mathrm{HCO}_{3}^{-}$, bicarbonate.

\section{Discussion}

This is the first prospective study to investigate the distribution of interfaces used for long-term NIV in COPD patients treated in a HMV center. The main results are as follows. 1) The predominant interface for COPD patients undergoing

Table 2 Ventilation settings and interfaces

\begin{tabular}{ll}
\hline Variable & $\mathbf{N}=\mathbf{I} \mathbf{2 3}$ \\
\hline IPAP (mbar) & $23.2 \pm 4.6$ \\
EPAP (mbar) & $5.8 \pm 1.3$ \\
BR/minute & $16.7 \pm 2.4$ \\
PSV (\%) & $52.8(65)$ \\
aPCV (\%) & $47.2(58)$ \\
Full-face mask & $77.2(95)$ \\
Nasal mask & $22.8(28)$ \\
Active exhalation valve & $32.5(40)$ \\
Active humidification & $87.0(107)$ \\
NIV compliance (hours/day) & $6.5(12 \mathrm{I})$ \\
\hline
\end{tabular}

Note: Data presented as mean \pm standard deviation or $\%$ of patients $(n=)$; data in brackets represent $n=x$.

Abbreviations: IPAP, inspiratory positive airway pressure; EPAP, expiratory positive airway pressure; BR, breathing rate; PSV, pressure support ventilation; aPCV, assisted pressure-controlled ventilation; NIV, noninvasive ventilation. 


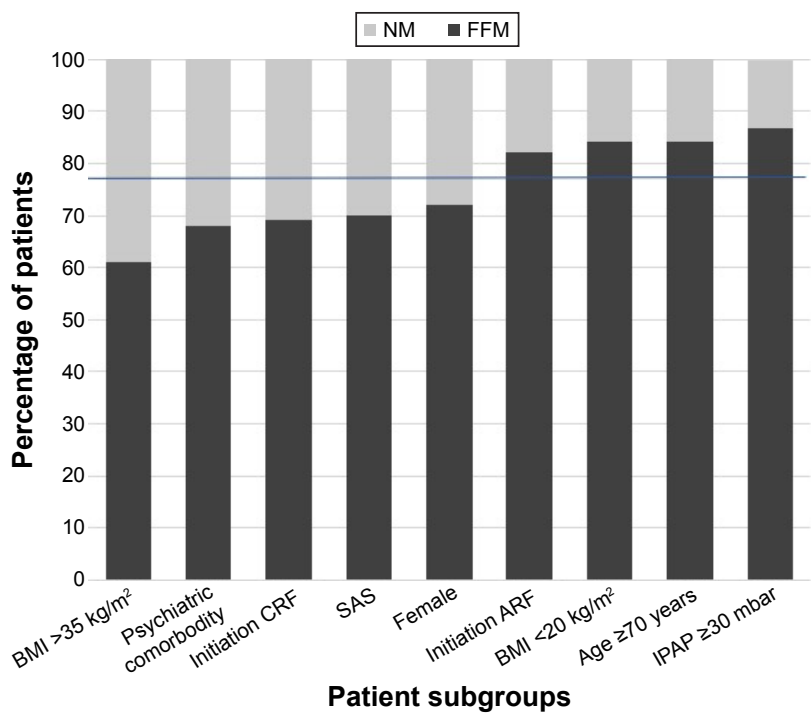

Figure 2 Distribution of oro-nasal masks (FFMs, dark gray) and NMs (light gray) in different subgroups of patients.

Note: Blue horizontal line indicates overall mean percentage of patients with FFM. Abbreviations: FFM, full-face mask; NM, nasal mask; BMl, body mass index (in $\mathrm{kg} / \mathrm{m}^{2}$ ); CRF, chronic respiratory failure; SAS, sleep apnea syndrome; ARF, acute respiratory failure; IPAP, inspiratory positive airway pressure.

NIV was the FFM, which was used in three out of four of the study patients. In contrast, only $22 \%$ of patients were treated by NMs. 2) Subgroup analysis revealed a higher percentage of NM use in patients with a BMI $>35 \mathrm{~kg} / \mathrm{m}^{2}$, psychiatric comorbidities, coexisting sleep apnea syndrome (SAS) and NIV initiation due to stable chronic respiratory failure and in female patients. In contrast, an increased number of FFMs

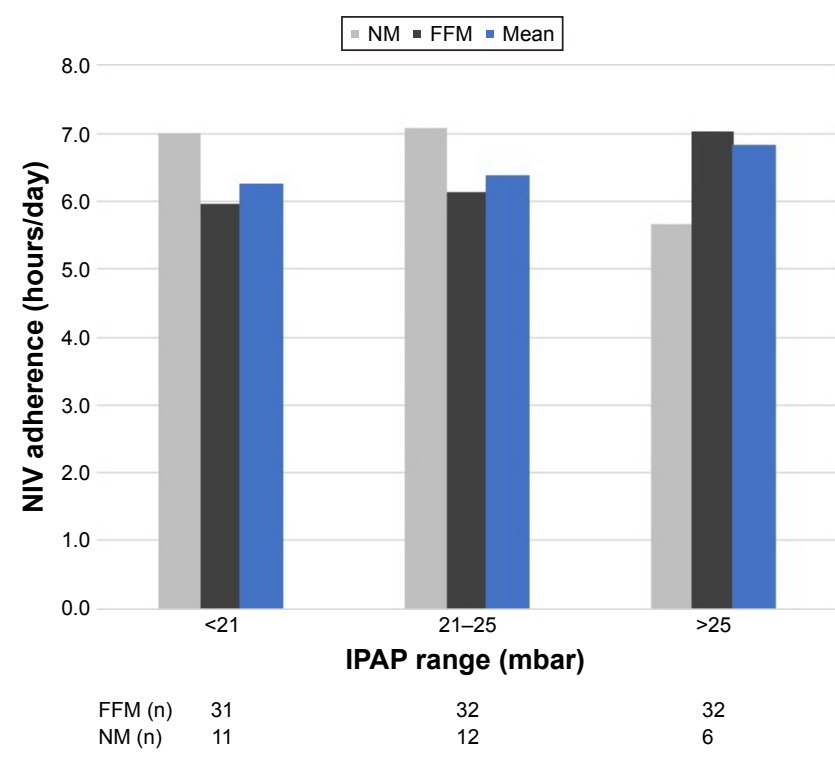

Figure 3 NIV adherence of patients with FFMs or NMs in varying IPAP ranges. Note: NIV adherence is presented in mean hours/day.

Abbreviations: NIV, noninvasive ventilation; NM, nasal mask; IPAP, inspiratory positive airway pressure; FFM, full-face mask.

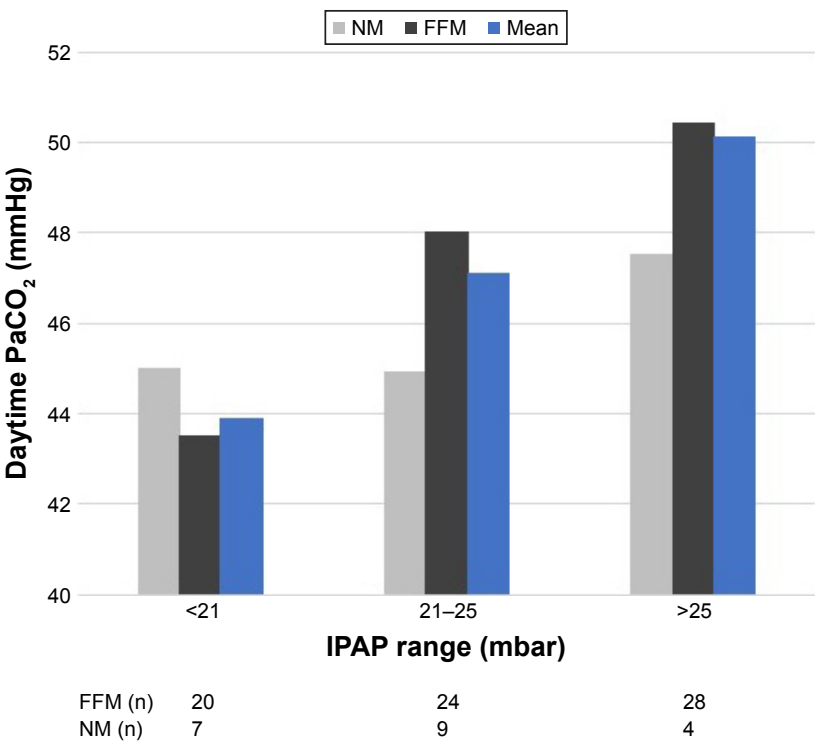

Figure 4 Daytime $\mathrm{PaCO}_{2}$ in relation to different IPAP ranges and interfaces. Note: Patients with acute exacerbation were excluded.

Abbreviations: $\mathrm{PaCO}_{2}$, arterial pressure of carbon dioxide; IPAP, inspiratory positive airway pressure; FFM, full-face mask; NM, nasal mask.

were applied in patients with IPAP $>30$ mbar, age $\geq 70$ years, BMI $<20 \mathrm{~kg} / \mathrm{m}^{2}$ and NIV initiation due to prolonged hypercapnia after acute respiratory failure. 3) Patients showed a good overall NIV compliance of 6.5 hours/day, regardless of the type of mask used, with only minor differences, depending on IPAP levels. 4) Daytime $\mathrm{PaCO}_{2}$ following nocturnal NIV ranged from normocapnic to slightly hypercapnic, either

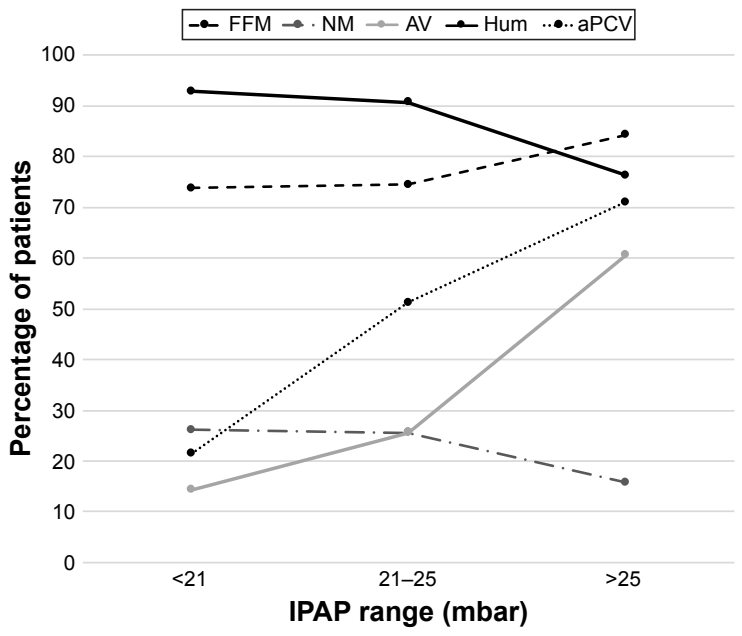

Figure 5 Distribution of NIV equipment and settings according to IPAP range. Notes: Group A (A): IPAP <2I mbar, Group B (B): IPAP 2I-25 mbar (B) and Group $C(C)$ : IPAP $>25$ mbar. Number of patients with FFMs: $A=31, B=32$ and $C=32$; with NMs: $A=11, B=12$ and $C=6$; with $A V: A=6, B=11$ and $C=23$; with Hum: $A=39, B=39$ and $C=29$ and with aPCV: $A=9,=22$ and $C=27$.

Abbreviations: NIV, noninvasive ventilation; IPAP, inspiratory positive airway pressure; FFM, full-face mask; NM, nasal mask; AV, active valve circuit; Hum, active humidification; aPCV, assisted pressure-controlled ventilation. 
with NMs or FFMs. 5) Increased IPAP levels were associated with an increased application of active exhalation valves and a preference for the aPCV mode, whereas the use of active humidification decreased within this setting.

The results of the current investigation are in contrast to those of the Eurovent survey published in 2005 by LloydOwen et al. ${ }^{9}$ In this HMV survey performed in 2001, NMs were reported as the main interface in use, with application in $80 \%$ of patients with underlying lung disease. However, these data arose from a survey and were not prospectively collected. Nevertheless, the findings are in line with two prospective randomized studies carried out at that time in Italy, in which NMs were exclusively used. ${ }^{6,7}$ Furthermore, the present results, as well as those from Struik et al, ${ }^{4}$ highlight the possibility of a substantial change in interface selection over the last 2 decades.

In line with the current findings, Struik et $\mathrm{al}^{4}$ recently applied FFMs in a trial addressing the role of long-term NIV in COPD patients in whom hypercapnia persisted after receiving ventilatory support for acute respiratory failure. This exclusive use of FFMs might be explained by the fact that NIV was initiated during acute exacerbations, which can have an important impact on the interface adopted for long-term use thereafter. Accordingly, a previous study on acute respiratory failure showed less NIV failure along with improved ventilation and tolerance in the presence of FFMs, ${ }^{14}$ thus broadening the potential use of FFMs in acute care. The current study also contained a large proportion of patients ( $\sim 60 \%$ of the cohort) in whom NIV was initiated and continued after acute exacerbation, which might have influenced the high usage of FFMs. As a result, patients might continue to use their interfaces once they have been successfully implemented, although this remains speculative.

Data on the selection of interfaces for chronic hypercapnic COPD and subsequent NIV initiation are unfortunately sparse. Köhnlein et $\mathrm{al}^{3}$ only enrolled patients with chronic hypercapnic respiratory failure for the initiation of NIV, and while this trial did support the use of long-term NIV in COPD, there is no information provided about interface distribution.

In addition, evolving ventilation techniques could partially explain the observed changes in interface distribution. Reflecting the development of NIV therapy in COPD, there is a clear trend of applying higher IPAP levels in order to achieve augmented ventilation and positive outcomes. ${ }^{1-4}$ Of note, the current study observed that real-life IPAP levels reach a mean of 23 mbar, which is in line with recent RCTs by Köhnlein et $\mathrm{al}^{3}$ (mean IPAP of 22 mbar) and Struik et $\mathrm{al}^{4}$ (mean IPAP of $21 \mathrm{mbar}$ ). In contrast, previous studies that exclusively used NMs applied lower mean IPAP levels between 12 and $18 \mathrm{~cm} \mathrm{H}_{2} \mathrm{O}^{5-7}$ Although the recent studies ${ }^{3,4}$ revealed beneficial effects of NIV on long-term survival, $\mathrm{PaCO}_{2}$ reduction and HRQL, the influence of the different masks on these parameters was not evaluated and therefore remains unclear. Interestingly, Dreher et al successfully used both NMs and FFMs in their experimental trial, comparing the effects of HI-NIV vs NIV at lower IPAP ranges on chronic hypercapnic COPD. Mean IPAP levels in the HI-NIV arm were even higher (29 mbar) than in the present study, and seven patients used NMs, while six patients used FFMs. ${ }^{2}$ However, an increased incidence of leakages was identified in patients with HI-NIV compared to those with lower IPAP levels. ${ }^{2}$ Therefore, the decision to apply FFMs instead of NMs could also be made on the basis of avoiding unintentional leakages. Nevertheless, it has been clearly demonstrated that a certain number of patients are able to successfully use NMs in association with high IPAP levels during chronic care. Accordingly, we identified several patients who effectively used NMs in combination with IPAP levels $>25$ mbar. Furthermore, Windisch et $\mathrm{al}^{1}$ exclusively recommended NMs as the first choice of interface in their review of HI-NIV in stable chronic hypercapnic COPD, whereas a switch to FFMs was advised in the event of mouth leakage. In light of this evidence, the question remains from a physiological perspective as to which type of mask for long-term COPD patients treated with high IPAP levels is the optimal one. Therefore, additional prospective randomized crossover studies are needed to answer this question.

Since the mask serves as an essential connection between the natural airways of the patient and the artificial airways of ventilator, the choice of the mask could have a potentially major impact on the patient's compliance. In the current trial, an overall mean NIV adherence of 6.5 hours/day was observed, which was similar to what has been reported in the latest RCTs. ${ }^{3,4}$ A recent meta-analysis demonstrated beneficial effects of HMV in COPD if patients showed an adherence to NIV for $>5$ hours/day, ${ }^{15}$ which, incidentally, was achieved by $70 \%$ of our cohort. In contrast, only $6 \%$ of our collective showed an adherence of $<1$ hour/day. In contrast, in the Dutch RCT, only $43 \%$ of the intentionto-treat group used NIV for $>5$ hours/day. ${ }^{4}$ An early study of long-term NIV in COPD even documented dropout rates of $\sim 50 \%$ during the 6 -month follow-up. ${ }^{16}$ Considering the real-life character of the current study, overall compliance was deemed to be satisfactory. When NMs and FFMs were compared in terms of compliance, only minor differences 
were observed, such as a tendency toward increased adherence with NMs or FFMs for IPAP levels $\leq 25$ mbar or $>25$ mbar, respectively. Of note, NMs were used in just six patients with IPAP levels $>25$ mbar and in only two patients with IPAP levels $>30$ mbar. However, Dreher et al revealed a very high adherence to NIV for mean IPAP levels of 29 mbar with both NMs and FFMs. Other studies showed increased compliance rates and sleep quality with NMs if excessive mouth breathing was ruled out. ${ }^{11,17}$ Again, these studies included only a few COPD patients with low IPAP levels. In addition, bench studies revealed increasing leakage under rising IPAP levels. ${ }^{18}$ The appearance of leakage itself might lead clinicians to switch to FFMs.

The subgroup of patients with coexisting SAS showed a higher number of NMs (30\%) compared to the overall mean. Previous studies on patients with obstructive SAS showed that NMs rather than FFMs were associated with improved sleep quality and compliance, as well as a lower apneahypopnea index. ${ }^{19,20}$ Therefore, in this particular cohort, a preference for NMs might be reasonable.

There were some limitations to the current trial that need to be addressed. First, the trial was carried out in a single center and therefore reflects the local NIV practices only. As a consequence, the results cannot be directly transferred to other centers or countries. However, it is important to note that the patient cohort and ventilation technique were similar to those in the German multi-centric trial by Köhnlein et al. ${ }^{3}$ Second, subjects in the current investigation were introduced to long-term NIV under different circumstances. Some received NIV following acute exacerbation and others during a stable phase of their disease; this is therefore suggested to lead to a bias regarding interface selection. Finally, this study should be regarded as a pilot trial on the use of interfaces, corresponding NIV settings and patient compliance, and the results should thus be considered with caution.

\section{Conclusion}

This study demonstrated that FFMs are currently the most commonly used interface for long-term NIV in COPD patients in a German respiratory center specialized in home mechanical ventilation, where three out of four patients used an interface that covered the nose and mouth. This trend is suggested to be associated with the increasingly higher IPAP levels that are associated with more modern NIV techniques. However, an individual approach to mask selection remains state of the art, and NMs are still reportedly successful, even with higher IPAP levels. Therefore, additional physiological studies are needed to determine the effects of different interfaces on long-term NIV for COPD patients.

\section{Acknowledgments}

We acknowledge all participants for the effort they devoted to this study. We acknowledge Dr Claudia Schmoor, Ph.D., for her helpful comments regarding the study design and Dr Sandra Dieni, Ph.D., for proofreading the manuscript.

This study was supported by a research grant from VitalAire GmbH, Germany. The study group received also research grants from Weinmann GmbH \& Co. KG, VIVISOL $\mathrm{GmbH}$ and Heinen und Löwenstein $\mathrm{GmbH} \& \mathrm{Co}$. KG, Germany, irrespective of the present study between 2013 and 2017.

The authors state that neither the study design, results, interpretation of the findings nor any other subject discussed in the submitted manuscript was dependent on financial support.

\section{Disclosure}

JC received speaking fees and travel funding from VitalAire. FSM received speaking/consulting fees from SenTec and Philipps Respironics and travel funding from Vivisol and Heinen und Löwenstein. SBS received speaking/consulting fees from Philipps Respironics and travel funding from SenTec and Heinen und Löwenstein. WW received speaking fees from Heinen und Löwenstein, VitalAire, ResMed, Sentec, Maquet, and Vivisol. JHS received speaking/consulting fees and/or travel funding from Heinen\&Löwenstein, VitalAire, ResMed, Linde, Radiometer, Keller Medical, Weinmann, Fisher\&Paykel, GHD Gesundheits GmbH, Breas Medical, Respironics, and SenTec AG. MB and ST report no conflicts of interest in this work and JC, FSM, SBS, WW, and JHS report no other conflicts of interest in this work.

\section{References}

1. Windisch W, Haenel M, Storre JH, Dreher M. High-intensity noninvasive positive pressure ventilation for stable hypercapnic COPD. Int J Med Sci. 2009;6(2):72-76.

2. Dreher M, Storre JH, Schmoor C, Windisch W. High-intensity versus low-intensity non-invasive ventilation in patients with stable hypercapnic COPD: a randomised crossover trial. Thorax. 2010;65(4):303-308.

3. Köhnlein T, Windisch W, Köhler D, et al. Non-invasive positive pressure ventilation for the treatment of severe stable chronic obstructive pulmonary disease: a prospective, multicentre, randomised, controlled clinical trial. Lancet Respir Med. 2014;2(9):698-705.

4. Struik FM, Sprooten RT, Kerstjens HA, et al. Nocturnal non-invasive ventilation in COPD patients with prolonged hypercapnia after ventilatory support for acute respiratory failure: a randomised, controlled, parallel-group study. Thorax. 2014;69(9):826-834. 
5. McEvoy RD, Pierce RJ, Hillman D, et al; Australian trial of non-invasive Ventilation in Chronic Airflow Limitation (AVCAL) Study Group. Nocturnal non-invasive nasal ventilation in stable hypercapnic COPD: a randomised controlled trial. Thorax. 2009;64(7):561-566.

6. Clini E, Sturani C, Rossi A, et al; Rehabilitation and Chronic Care Study Group, Italian Association of Hospital Pulmonologists (AIPO). The Italian multicentre study on noninvasive ventilation in chronic obstructive pulmonary disease patients. Eur Respir J. 2002;20(3):529-538. Erratum in: Eur Respir J. 2002;20(6):1617.

7. Casanova C, Celli BR, Tost L, et al. Long-term controlled trial of nocturnal nasal positive pressure ventilation in patients with severe COPD. Chest. 2000;118(6):1582-1590.

8. Elliott MW. The interface: crucial for successful noninvasive ventilation. Eur Respir J. 2004;23(1):7-8.

9. Lloyd-Owen SJ, Donaldson GC, Ambrosino N, et al. Patterns of home mechanical ventilation use in Europe: results from the Eurovent survey. Eur Respir J. 2005;25(6):1025-1031.

10. Crimi C, Noto A, Princi P, et al. Domiciliary non-invasive ventilation in COPD: an International Survey of Indications and Practices. COPD 2016;13(4):483-490.

11. Willson GN, Piper AJ, Norman M, et al. Nasal versus full face mask for noninvasive ventilation in chronic respiratory failure. Eur Respir J. 2004;23(4):605-609.

12. Navalesi P, Fanfulla F, Frigerio P, Gregoretti C, Nava S. Physiologic evaluation of noninvasive mechanical ventilation delivered with three types of masks in patients with chronic hypercapnic respiratory failure. Crit Care Med. 2000;28(6):1785-1790.

13. Windisch W, Walterspacher S, Siemon K, Geiseler J, Sitter H; German Society for Pneumology. Guidelines for non-invasive and invasive mechanical ventilation for treatment of chronic respiratory failure. Published by the German Society for Pneumology (DGP). Pneumologie. 2010;64(10):640-652.
14. Girault C, Briel A, Benichou J, et al. Interface strategy during noninvasive positive pressure ventilation for hypercapnic acute respiratory failure. Crit Care Med. 2009;37(1):124-131.

15. Struik FM, Lacasse Y, Goldstein RS, Kerstjens HA, Wijkstra PJ. Nocturnal noninvasive positive pressure ventilation in stable COPD: a systematic review and individual patient data meta-analysis. Respir Med. 2014;108(2):329-337. Review.

16. Criner GJ, Brennan K, Travaline JM, Kreimer D. Efficacy and compliance with noninvasive positive pressure ventilation in patients with chronic respiratory failure. Chest. 1999;116(3):667-675.

17. Teschler H, Stampa J, Ragette R, Konietzko N, Berthon-Jones M. Effect of mouth leak on effectiveness of nasal bilevel ventilatory assistance and sleep architecture. Eur Respir J. 1999;14(6):1251-1257.

18. Schettino GP, Tucci MR, Sousa R, Valente Barbas CS, Passos Amato MB, Carvalho CR. Mask mechanics and leak dynamics during noninvasive pressure support ventilation: a bench study. Intensive Care Med. 2001; 27(12):1887-1891.

19. Andrade RG, Madeiro F, Piccin VS, et al. Impact of acute changes in CPAP flow route in sleep apnea treatment. Chest. 2016;150(6): 1194-1201.

20. Borel JC, Tamisier R, Dias-Domingos S, et al; Scientific Council of The Sleep Registry of the French Federation of Pneumology (OSFP). Type of mask may impact on continuous positive airway pressure adherence in apneic patients. PLoS One. 2013;8(5):e64382.
International Journal of COPD

\section{Publish your work in this journal}

The International Journal of COPD is an international, peer-reviewed journal of therapeutics and pharmacology focusing on concise rapid reporting of clinical studies and reviews in COPD. Special focus is given to the pathophysiological processes underlying the disease, intervention programs, patient focused education, and self management protocols.

\section{Dovepress}

This journal is indexed on PubMed Central, MedLine and CAS. The manuscript management system is completely online and includes a very quick and fair peer-review system, which is all easy to use. Visit http://www.dovepress.com/testimonials.php to read real quotes from published authors. 